Eric Daniel Tenda ${ }^{1,2,4}$, Moses Mazmur Asaf1,4, Ariel Pradipta ${ }^{2,3}$, Meutia Ayuputeri Kumaheri³ Anindya Pradipta Susanto ${ }^{2,3}$

\title{
Editorial
}

\section{The COVID-19 surge in Indonesia: what we learned and what to expect}

From June 2021 until August 2021, Indonesia experienced an unprecedented surge in the number of daily new confirmed coronavirus disease 2019 (COVID-19) cases. We, as authors who saw these events unfold first-hand, would like to describe the extent of Indonesia's COVID-19 case surge, its effect on the healthcare system, and the fallout, in this editorial. Moreover, we aim to identify the root of the problems that could have caused the recent surge, and subsequently propose possible solutions.

Indonesia's previous record of the highest number of daily new confirmed cases was 14518 cases, recorded on 30 January 2021. On 15 July 2021, the number had increased almost four-fold to 56757 cases [1]. From 17 June 2021 to 22 August 2021, Indonesia recorded more than 10000 daily new cases consecutively, with an average of 30475 daily cases in that specific time period [1]. To put this into perspective, in that specific period, $\sim 2.04$ million people out of Indonesia's population of 270 million were infected with COVID-19. While these numbers are remarkable, some may argue that they do not reflect the true number of cases, and that in reality, the number of cases is much more significant. A survey conducted by Jakarta's health department, in conjunction with Universitas Indonesia, the Eijkman Institute for Molecular Biology and CDC Indonesia, in March 2021 found that the number of individuals in Jakarta that had COVID-19 antibodies was seven times higher than the official record for COVID-19 patients recorded in Jakarta [2]. Subsequently, this suggests the possibility that the real number of cases during the surge might be underreported.

Many experts attribute this unprecedented surge to the massive exodus during a national holiday in mid-May 2021. The government prohibited inter-city travel as a precaution, but scarcity of law enforcers and low compliance from citizens for various socioeconomic reasons led to an inefficient ban.

As the number of daily confirmed cases increased, so did the burden on healthcare facilities and healthcare practitioners. Cracks in the healthcare system began to show as the number of active COVID-19 cases accumulated and the healthcare system reached breaking point around early to mid-July 2021. Public health facilities were stretched thin, which led to longer waiting times and, in some cases, inadequate provision of healthcare supplies. This overload in demand for health services may have contributed more significantly to the increase in mortality rate. Supply of oxygen and medicines began to dwindle, and hospital bed occupancy rate (BOR) was at an alltime high.

Based on the report released by the Indonesian Ministry of Health on 15 July 2021, six provinces had a hospital BOR of over $80 \%$ (Banten $90 \%$, DI Yogyakarta 89\%, West Java 89\%, DKI Jakarta $88 \%$, Central Java $86 \%$, and East Java $82 \%$ ) [3]. A follow-up report was released on 23 July 2021 , and it showed that the number of provinces that had a hospital BOR of over $80 \%$ had decreased to only three provinces (DI Yogyakarta 85\%, East

@ERSpublications

Through the implementation of a test and trace system, disciplined public health measures, the acceleration of vaccinations, and a genome surveillance programme, LMICs such as Indonesia can prevent future outbreaks and survive the COVID-19 pandemic. https://bit.ly/3JBBSie

Cite as: Tenda ED, Asaf MM Pradipta A, et al. The COVID-19 surge in Indonesia: what we learned and what to expect. Breathe 2021; 17: 210146. 
Kalimantan 83\%, and Banten 81\%) [4]. However, this decrease in hospital BOR was not due to a decrease in the number of daily confirmed cases, rather it was due to hospitals installing emergency beds, exceeding their capacity by putting extra beds on parking spaces under huge tents that act as temporary buildings. From 1 June 2021 to 31 August 2021, the total number of confirmed deaths in Indonesia due to COVID-19 was 82445 , with an average of 896 deaths per day in that time period [5]. Furthermore, the surge also took its toll on healthcare practitioners. As reported by the Tim Mitigasi Pengurus Besar Ikatan Dokter Indonesia (Mitigation Team of the Indonesian Doctors Association) on 4 August 2021, a total of 251 doctors died due to COVID-19 from June 2021 to July 2021. In total, 769 healthcare workers (doctors, nurses, midwives, dentists, pharmacists, etc.) died due to COVID-19 in the period from June 2021 to August 2021 [6].

Apart from the massive exodus that happened during the national holiday in mid-May and lax discipline around public health measures, several reasons that could have exacerbated the recent surge of cases come to mind. First, the emergence of new variants. As an RNA virus, severe acute respiratory syndrome coronavirus 2 (SARS-CoV-2) is constantly mutating, shifting from the original SARS-CoV-2 viral genotype WIV 04 (hCoV-19/ Wuhan/WIV04/2019) to several variants found across the world. Indonesia itself hosted several COVID-19 variants, such as the Alpha (B.1.1.7), Beta (B.1.351) and Delta (B.1.617.2) variants, and the B.1.466.2 variant that originally emerged from Indonesia. From the end of 2020 to early 2021, genomic surveillance reported a significant portion of COVID-19 in Indonesia had already shifted from the wild-type WIV 04 to other variants, most notably the B.1.466.2 variant. Two mutations that are correlated to increased infectivity $[7,8]$ are commonly found in the B.1.466.2 variant: $\mathrm{N} 439 \mathrm{~K}$ (99.1\%) and P681R (69.7\%) [9]. Moreover, the Delta variant, which was classified as a variant of concern (VoC) by the World Health Organization (WHO) in May 2021 due to its possible ability to reduce vaccine efficacy, increased risk of hospitalisation and its increased transmissibility (as shown by its increased basic reproduction number $\left.\left(R_{0}\right)[10]\right)$, also became the predominant variant in Indonesia.

The second reason is Indonesia's low vaccination rate. Records show that on 1 June 2021, only $3.88 \%$ of Indonesia's 270 million population had been fully vaccinated, and on 1 August 2021, the fully vaccinated population had only increased to $7.48 \%$ [11]. While by virtue of population number alone Indonesia is still the top vaccinated Southeast Asian country, the percentage of a population that is fully vaccinated reflects how close a country is to achieving herd immunity and the possibility of transmission in that country. Although it is not guaranteed that a vaccinated person will be COVID19-free, vaccines have been shown to reduce disease severity, and thus lessen the burden on healthcare facilities [12-14]. Moreover, although the efficacy of vaccines is reduced in some $\mathrm{VoCs}$, a study by GeERs et al. [15] found that severe COVID19 could still be eluded with the protection of vaccines, as provided by cross-reactive SARS-CoV2-specific T-cell-mediated immunity.

It should also be noted that the CoronaVac (Sinovac Biotech, Beijing, China) is the dominant COVID-19 vaccine in Indonesia, as is the case in many other lower-middle income countries. This fact may also exacerbate Indonesia's low protection against VoCs, as proven by prior studies. A study by CHEN et al. [16] showed that, while a second dose of the CoronaVac is relatively effective in neutralising the original SARS-CoV-2 viral genotype as well as the Alpha variant, serum neutralisation efficacy was notably decreased against the Beta variant by a factor of 5.27 (95\% Cl 4.19-6.34). Moreover, the efficacy of a second dose of CoronaVac is also markedly decreased against the Delta variant compared with a second dose of the ChAdOx1 vaccine, as signified by its low geometric mean titre ( 21.2 versus 69.7 ) in the study by ANGKASEKWINAI et al. [17].

The recent COVID-19 surge in Indonesia has brought immeasurable sorrow to Indonesian citizens, but every dark cloud has a silver lining. Through this adversity, room for improvement in the healthcare system and government policies could be identified and rectified. While the surge in cases seemed like a rude wake-up call to Indonesians to exercise health protocols, strict mitigation policies that are enforced should still be set by the government. Aside from the highly suggestive biological influence on the increased transmission, different policies have various impacts on the spread of the virus [13]. Reports of other surges in cases around the world reasoned that premature loosening of health protocols led to the second or third wave of new infections [18, 19]. Although the argument remains whether the magnitude of effect from the variant is higher than effects from nonbiological factors such as premature easing of health protocols or opening up of travel restrictions, we discuss how each factor may provide an important learning experience during this pandemic.

As virus variants may influence the dynamics of the pandemic, SARS-CoV-2 genome sequencing could be a useful tool in predicting outbreaks and give healthcare facilities a head start to prepare their infrastructure and logistics and alert the government, which would lead to further measures. Acknowledging this, WHO published guidelines underlying the importance of early establishment of national surveillance using genome sequencing $[20,21]$. These guidelines highlight the importance of tracking variants to quickly to acknowledge if a variant is potentially more challenging to manage. According to a guideline by the European Centre for Disease Prevention and Control (ECDC), to detect a novel variant at a relative proportion of $2.5 \%$ (the 
recommended predicted percentage), a country with more than 100000 positive SARS-CoV-2 cases a week (such as Indonesia back in June 2021 to August 2021) needs to sequence 600 samples as fast as possible in that time period [22]. As an example, based on data we curated from covspectrum.org (enabled by GISAID), we found that in January 2021 the Delta variant first emerged in Indonesia and there were around 335000 positive cases in that period, yet only 709 genome sequencing samples were collected and analysed. This number is inadequate compared with the guidelines released by the ECDC.

At the time of writing (November 2021), COVID-19 RT-PCR testing facilities are widely available on all of Indonesia's five main islands (Sumatra, Java, Kalimantan, Sulawesi, and Papua) and major satellite islands (Bali, Nusa Tenggara Barat and Timur, Maluku, etc.). According to the Indonesian Ministry of Health's Research and Development Agency, a total of 894 laboratories spread across Indonesia are capable of conducting RT-PCR testing [23] and this number is expected to grow. These established labs may serve as the foundation for the integration of a nationwide genome sequencing campaign in Indonesia. Moreover, these labs and Indonesia's "PeduliLindungi" phone application serve as the foundations of Indonesia's test and trace system. The "PeduliLindungi" app, which roughly translates as "care and protect", records a person's vaccination status and RT-PCR results dynamically, provides information on vaccination registrations, and as a gatekeeper to stop unvaccinated persons from performing social activities. We believe that the proper utilisation of these infrastructures is pivotal in mitigating the spread of COVID-19. Nevertheless, a genome surveillance programme could further improve this already established system in preventing future outbreaks.

The development of an accurate and agile genome surveillance programme could open the path for studies linking genome sequencing data and clinical data. This project would require a strong integration of health records and a network of capable laboratories to perform timely SARS-CoV-2 sequencing. It would also require responsible and secure database capabilities to compile and analyse clinical and genomic data [24]. Through these studies, researchers could find the correlation between virus variants and potential clinical outcomes, which in turn could be used to predict how potentially impactful the outcome of an outbreak caused by a specific variant would be, thus providing the much-needed head start to prepare for it appropriately.

It is also imperative to improve vaccination rates in the future, as the recent surge has shown us how important vaccines are. According to a public survey by Charta Politika with 1200 respondents all around Indonesia, the number one problem Indonesians face in trying to get vaccinated is lack of information [25]. In this digital era, where almost all public information is accessible in the palm of your hands in the form of smartphones and tablets, it is quite ironic that lack of information is the number one problem stalling the process of vaccination. Nevertheless, we acknowledge that easily accessible information can be a double-edged sword, where educative and informative contents are as easily accessible as misinformation and hoaxes spread by irresponsible parties. To tackle this problem, a simple and straightforward public campaign through traditional and social media by the government explaining the importance of vaccines and how to get them could prove to be beneficial. Interestingly, a study by DAl et al. [26] in Los Angeles (California, USA) suggested that an act as simple as sending a reminder in the form of a text message 1 day after individuals become eligible for vaccines boosted vaccination rates by around 6\%. We should also consider Indonesia's level of education and literacy rate when addressing ease of information access, seeing as Indonesia is a lower-middle income country and amongst the top 10 worst countries in terms of literacy according to a survey conducted by the Program for International Student Assessment, which was presented by the Organization for Economic Co-operation and Development in 2019 [27].

We understand that implementing these proposed solutions evenly across Indonesia may pose some challenges, especially seeing as Indonesia is the largest archipelago in the world. For instance, the lack of healthcare workers and resource distribution in remote areas might hinder the acceleration of the vaccination process. While Indonesia has an adequate number of healthcare workers, most of them are concentrated on major islands. Moreover, the logistics needed to distribute the vaccines and healthcare workers require significant time, resources, and manpower. In the case of the genome surveillance programme, remote areas need to send their samples to more accessible areas, as these remote areas generally do not have the necessary infrastructure nor equipment to do the sequencing themselves. This also needs significant resources and care, as a poor effort in transporting the samples may render them futile for analysis. However, Indonesia's unique geographical features helped isolate some of these remote areas from major outbreaks, unlike the more densely populated areas in Indonesia. Nevertheless, protecting these remote areas from a potential COVID-19 surge is also necessary.

While we propose the implementation of a genome surveillance programme and the improvement of vaccination rates through supporting policies, readers should be cognisant of the fact that we still endorse the enforcement of public health measures, and the test and trace system and infrastructure already established in Indonesia as well. We believe that public health measures and the test and trace system and infrastructure 
are still at the heart of the COVID-19 mitigation protocol and are pivotal in controlling the pandemic. A constant reminder for the population to wear a mask, practise hand hygiene, and social distancing should be promoted by the government using a social media and traditional media campaign. Moreover, the test and trace system should be practised with vigilance, and the infrastructure should be improved upon when necessary. A genome surveillance programme and improvement in vaccination rate should serve as adjuncts to the already established public health measures and the test and trace system and infrastructure in Indonesia, not replace it nor take precedence over it.

Ultimately, although much has been lost in the recent COVID-19 "tsunami", it would be wise to learn and grow from it. These gruelling challenges require intricate measures to address, yet we believe that they are not insurmountable. Through the enforcement of public health measures and the test and trace system and infrastructure already established in Indonesia, as well as the implementation of policies that benefit the process of vaccination and genome sequencing, while considering socioeconomic challenges and Indonesia's overall education level, we believe that Indonesia can survive through the pandemic. We also hope that other lower-middle income countries can learn from Indonesia's experience. Seeing as the surge in Indonesia unfolded following a major public holiday and we are approaching holiday season, where many people celebrate different cultural and religious holidays, we hope that the necessary precautions can be taken facing these holidays. Vaccination efforts should be sped up prior to these holidays, national and international travel restrictions should be considered and enforced if possible, and healthcare institutions and supplies should be prepared for the months following these holidays.

\section{Affiliations \\ Eric Daniel Tenda ${ }^{1,2,4}$, Moses Mazmur Asaf ${ }^{1,4}$, Ariel Pradipta ${ }^{2,3}$, Meutia Ayuputeri Kumaheri Anindya Pradipta Susanto 2,3 \\ 1Division of Respirology and Critical IIIness, Dept of Internal Medicine, Faculty of Medicine Universitas Indonesia, Dr. Cipto Mangunkusumo National General Hospital, Jakarta, Indonesia. ${ }^{2}$ Indonesia Medical Education and Research Institute (IMERI), Faculty of Medicine, Universitas Indonesia, Jakarta, Indonesia. ${ }^{3} \mathrm{Genomik}$ Solidaritas Indonesia (CSI) Lab, Jakarta, Indonesia. ${ }^{4}$ Contributed equally as co-first authors.}

\section{Conflict of interest}

None declared.

\section{References}

1. Johns Hopkins University \& Medicine. COVID-19 Data Repository by the Center for Systems Science and Engineering (CSSE) at Johns Hopkins University, 2021. https://coronavirus. jhu.edu/

2. Jakarta Globe. Jakarta Nears Herd Immunity as Half of Its Population Have Had Covid-19: Survey. Date last updated: 11 July 2021. https://jakartaglobe.id/news/jakarta-nears-herdimmunity-as-half-of-its-population-have-had-covid19-survey

3. Kementerian Kesehatan Republik Indonesia. Rekap tempat tidur covid di rs Sumber data: pelaporan covid di rs 5 juli 2021 jam 13.00 wib. www.kemkes.go.id/downloads/resources/ download/Ketersediaan-Tempat-Tidur-RS-Covid19/BORRS-5-JULI-2021.pdf

4. Kementerian Kesehatan Republik Indonesia. Rekap tempat tidur covid di rs Sumber data: pelaporan covid di rs 23 juli 2021 jam 13.00 wib. https://www.kemkes.go.id/downloads/ resources/download/Ketersediaan-Tempat-Tidur-RSCovid19/BOR-RS-23-JULI-2021.pdf

5. Our World in Data. Coronavirus (COVID-19) Deaths. https:// ourworldindata.org/covid-deaths

6. Lapor COVID-19, Pusara Digital Tenaga Kesehatan. https:// nakes.laporcovid19.org/statistik

7. Harvey WT, Carabelli AM, Jackson B, et al. SARS-CoV-2 variants, spike mutations and immune escape. Nat Rev Microbio/ 2021; 19: 409-424.

8. Saito A, Nasser $H$, Uriu K, et al. SARS-CoV-2 spike P681R mutation enhances and accelerates viral fusion. bioRxiv 2021; preprint [https://doi.org/10.1101/2021.06.17.448820].
9. Cahyani I, Putro EW, Ridwanuloh AM, et al. Genome profiling of SARS-CoV-2 in Indonesia, ASEAN, and the neighbouring East Asian countries: features, challenges, and achievements. bioRxiv 2021; preprint [https://doi. org/10.1101/2021.07.06.451270].

10. Liu Y, Rocklöv J. The reproductive number of the Delta variant of SARS-CoV-2 is far higher compared to the ancestral SARS-CoV-2 virus. J Travel Med 2021; 28: taab124.

11. Our World in Data. Share of the population fully vaccinated against COVID-19, Jul 31, 2021. https:// ourworldindata.org/explorers/coronavirus-dataexplorer?time $=2021-07-31 \&$ facet $=$ none \&Metric $=$ People + fully+vaccinated\&Interval=7-day+rolling+average\&Relative +to+Population=true\&Align+outbreaks=false

12. Zhang $Y$, Zeng $G$, Pan $H$, et al. Safety, tolerability, and immunogenicity of an inactivated SARS-CoV-2 vaccine in healthy adults aged $18-59$ years: a randomised, double-blind, placebo-controlled, phase $1 / 2$ clinical trial. Lancet Infect Dis 2021; 21: 181-192

13. Voysey M, Costa Clemens SA, Madhi SA, et al. Safety and efficacy of the ChAdOx1 nCoV-19 vaccine (AZD1222) against SARSCoV-2: an interim analysis of four randomised controlled trials in Brazil, South Africa, and the UK. Lancet 2021; 397: 99-111.

14. Lopez Bernal J, Andrews N, Gower C, et al. Effectiveness of Covid-19 vaccines against the B.1.617.2 (Delta) variant. $N$ EnglJ Med 2021; 385: 585-594.

15. Geers D, Shamier MC, Bogers $S$, et al. SARS-CoV-2 variants of concern partially escape humoral but not T-cell 
responses in COVID-19 convalescent donors and vaccinees. Sci Immunol 2021; 6: eabj1750

16. Chen $Y$, Shen $H$, Huang $R$, et al. Serum neutralising activity against SARS-CoV-2 variants elicited by CoronaVac. Lancet Infect Dis 2021; 21: 1071-1072.

17. Angkasekwinai N, Sewatanon J, Niyomnaitham S, et al. Safety and immunogenicity of CoronaVac and ChAdOx 1 against the SARS-CoV-2 circulating variants of concern (Alpha, Delta, Beta) in Thai healthcare workers. medRxiv 2021; preprint [https://doi.org/10.1101/2021.10.03.21 264451].

18. Seong H, Hyun HJ, Yun JG, et al. Comparison of the second and third waves of the COVID-19 pandemic in South Korea: importance of early public health intervention. Int J Infect Dis 2021; 104: 742-745.

19. Choudhary OP, Priyanka, Singh I, et al. Second wave of COVID-19 in India: dissection of the causes and lessons learnt. Travel Med Infect Dis 2021; 43: 102126.

20. World Health Organization. Genomic sequencing of SARS-CoV-2: a guide to implementation for maximum impact on public health. Geneva, World Health Organization, 2021.

21. World Health Organization. SARS-CoV-2 genomic sequencing for public health goals: Interim guidance
(WHO/2019-nCoV/genomic_sequencing/2021.1). Geneva, World Health Organization, 2021.

22. European Centre for Disease Prevention and Control. Guidance for Representative and Targeted Genomic SARSCoV-2 Monitoring - 3 May 2021. Stockholm, ECDC, 2021.

23. Badan Litbangkes Kementrian Kesehatan RI. Daftar Laboratorium Jejaring Pemeriksa Covid-19 Yang Input Ke Dalam Nar Selama 3 Minggu Terakhir. www.litbang.kemkes. go.id/laboratorium-pemeriksa-covid-19/

24. Oude Munnink BB, Nieuwenhuijse DF, Stein M, et al. Rapid SARS-CoV-2 whole-genome sequencing and analysis for informed public health decision-making in the Netherlands. Nat Med 2020; 26: 1405-1410.

25. Charta Politika. Kendala dalam Melakukan Vaksinasi. Date last updated: 12 August 2021

26. Dai H, Saccardo S, Han MA, et al. Behavioural nudges increase COVID-19 vaccinations. Nature 2021; 597 : 404-409.

27. Kementrian Dalam Negeri Republik Indonesia. Tingkat literasi Indonesia di dunia rendah, ranking 62 dari 70 negara [Indonesia's literacy level in the world is low, rank 62 out of 70 countries]. https://perpustakaan.kemendagri.go.id/?p=4661 Date last updated: 23 March 2021. 